\title{
Assessment Approach to the Interconnections of Social Network Radical Online Communities Based on Open Data Analysis with the Use of TF-IDF
}

\author{
Aleksei Savelev ${ }^{1}{ }^{*}$ Anastasiia Kaida ${ }^{1}$, Anna Karpova $^{1}$ \\ ${ }^{1}$ Tomsk Polytechnic University, Russia \\ *Email: sava@tpu.ru
}

\begin{abstract}
Online-radicalization researches automation is considered to be one of the currently important tasks of contemporary sociology. On one side, the Internet data accessibility, including social networks data, provides unique opportunities from the perspective of coverage of the phenomena and processes under study. On the other side, notwithstanding the increased availability of Data Science tools, the potency of their use depends equally on both the corresponding skills and the applied subject area competence. The present work introduces the experience of an interdisciplinary research group in adapting and applying the automated data harvesting and preprocessing tools of online radicalization. Assessment toolkit of words relevancy in posts has been considered on the basis of TF-IDF statistical measure. The hypothesis about the closedness of radical on-line communities in "echo-chambers" has been verified and partially confirmed.
\end{abstract}

Keywords: Online-radicalization, Social media mining, Content-analysis, Tf-idf.

\section{INTRODUCTION}

Nowadays the use of contemporary Internet technologies by representatives of radical ideological platforms is one of the most discussed problems at the level of politicians, security agencies, scientists and society as a whole. Ultra-radical communities apply various targeting technologies to advance their goals and effect radicalization online. Real-time tracking of such content on social media is important for security analysts. From the point of view of M. Hall, M.K. Logan, G.S. Ligon and D.C. Derrick, authors of the work "Do Machines Replicate Humans? Toward a Unified Understanding of Radicalizing Content on the Open Social Web», the easiness of destructive content spreading, as well as a variety of its delivery methods provide radical communities with access to a massive audience, which allows solving the problems of searching and recruiting supporters, spreading ideologically significant information, attracting resources and providing general management [1]. Herewith, the Internet itself is not the cause of radicalization, but only a toolkit platform that provides previously unreachable massiveness and speed of social communications. Responding to the arisen threats, together with the development and the use cost reduction of data mining methods, the interdisciplinary direction of Social Media Mining is developing. The study of destructive content, which promotes radical ideas, is an example of a field where social media has a huge impact. The gathered social network data can be analyzed to study "digital footprints", the social network users' behavior, motivation and technologies for ultra-radical content promotion.

The basic research directions in the field of studying the process of radicalization with the help of an interdisciplinary approach in world science can be classified into the following areas:

1. Data profiling methods development and enhancement ("digital footprint") to organize a system of operational diagnostics of destructive information and psychological impact threats of terrorist orientation, 
involvement risks of target youth groups in extremist and terrorist activities [2-3].

2. The improvement of methods and tools of computational linguistics. Development of dictionaries, linguistic markers highlighting with the use of automated text analysis methods: dictionaries of words-triggers related to the terrorist propaganda, extremist clichés [4$6]$.

3. Research of complex, random distributed data to identify mechanisms, levels and indicators of youth radicalization, by means of the analysis of discourse and dynamics of the Internet network communities. Prototypes development for the narrow-topic tasks of social networks data analysis to define risk groups/clusters in social networks, to identify various radical ideological platforms of individual and group mobilizing dynamics to commit violent incidents [7-8].

4. Role-based modeling. Defining various types of influence, imitation and inspiration; classification of behavior patterns, trajectories and influence results; development of a hierarchical structure of microlevel role-based behavior models corresponding to subtypes [9-11].

5. Social connections analysis in Internet network communities; development of social bonds typology. Defining and classifying behavioral, emotional, operational and personal mechanisms of radicalization, identifying external factors of influence in online radicalization. Determination of the external influence degree, ideological influential factors and, accordingly, predicting behavioral trajectories, the moment of transition to the terminal stage, identifying the target and methods of attack [12-13].

The purpose of our research is to establish the existence and to assess the bond strength between social network communities belonging to various ideological platforms. The task described in the present work is to test with the help of the experiment the hypothesis that radical online communities are structurally closed in "echo chambers" which increase messages within communities and suppress any external influence. This is manifested by the lack of a significant number of common topics and subscribers.

\section{RESEARCH METHODOLOGY}

The generalized research methodology is described by the following sequence of actions:

1. Expert choice of ultra-radical online social network communities that belong to various ideological platforms.

2. Automated assessment of relevant words used in community posts:
2.1 Automated information retrieval of the 100 most recently published posts.

2.2 Developing texts single corpus of radical online communities and their preprocessing (words normalization, punctuation marks removal, stop words removal).

2.3 Assessment of each word relevance of an individual post based on the TF-IDF statistical measure.

2.4 Creation of the most relevant words list for each radical ideological platform.

3. The search of the relevant crossing words for various ideological platforms (to assess the similarity of the discussed topics).

4. Automated search of radical online communities audience crossing:

4.1 Retrieving of subscription information for each community.

4.2 Searching of unique followers crossing.

4.3 The crossing level generalization and assessment.

5. Reading of the obtained results.

\subsection{Expert choice of radical online communities}

The expert selected 32 communities of the social network VKontakte, which belong to four different classes: Alt-right, MGTOW (men going their own way), AntiFa and anarchs.

For ultra-radical communities of different classes, taken as an experiment, the role of ideology is decisive, since it allows justifying even violent actions in a wider value criteria system (even deviant ones). Communities, though different in many ways, but endorse, promote and justify the use of violence as a means to achieving a goal. The dominant principles that govern group organization are described below.

Alt-right communities are based on promoting the idea of white supremacy (White Power) and the conduct of "holy racial war" (RaHoWa). Alt-right, as a movement, originates from Richard Spencer, a famous white nationalist who invented the term itself and had a goal to gather the widest possible group of "racist realists" [14]. Movement supporters rely on the principles of suprematism, nativism and the principle of segregation. The enmity and hatred manifestation among these communities is aimed at immigrants and Muslims. Communities of this kind are spreading ideas about the genocide of the white population, as well as calls for organized resistance. The fact that Alt-right is an almost exclusively online phenomenon sets it apart from other ultra-right subcultures and movements. 
The MGTOW communities in the most general sense are united by the idea of "hostile sexism", the essence of which is that men believe that they are threatened by women, even if the threats are mainly indirect and political, rather than explicit and physical. The idea of "hostile sexism" has gained considerable popularity and wide-spreading among the ultra-right movements, it operates mainly on the Internet and promotes the main idea of separating men from women, countering the spread of feminism, avoiding marriage and serious relationships with women. This class of communities is extremely categorical in its hateful attitude towards women, blames them for all the troubles, and promotes the genetic superiority of men.

The AntiFa communities support and promote the ideas of an international movement, which declares its goal to fight against fascism, neo-nazism and racism. The movement is not homogeneous, it has a rather wide range of ideological convictions and it crosses "borders" in its modern incarnation from non-violent methods of achieving and advancing towards the goal to increasingly harsh illegal violent methods.

Anarchist communities also have a wide range of ideological views, their basic beliefs based on personal freedom, and have the goal of eliminating all types of coercion and exploitation of man by man. Anarchists adhere to anti-state views, promote the ideas of organized resistance and the creation of a society like a confederation on the basis of the voluntary cooperation of individuals, personal interest, organized self- government and the assignment of responsibility to each member of such a voluntary association.

Table 1 provides information on the communities chosen by the expert for analysis. Community names have been changed to counter the proliferation and replication of ultra-radical community ideas.

\subsection{Automated assessment of relevant words used}

Hypothesis experimental testing was conducted on the basis of open data from the Russian social network "VKontakte". The data was retrieved using the VK API. Retrieved data types: online community name, post text, list of subscribers. Data that allows identifying the user and other personal information were not collected or processed.

All the retrieved posts were combined into a single text corpus. For all post words a measure of the word relevance for the post was determined with the use of the TF-IDF statistical measure:

$$
\text { weight }(w, p)=\frac{n_{w}}{\sum_{k} n_{k}} \times \log \frac{|P|}{\left|\left\{p_{i} \in P \mid w \epsilon p_{i}\right\}\right|}
$$

where

$n_{w}$ - number of word occurrence $w$ in a post,

$\sum_{k} n_{k}-$ total number of words in a post,

$w-$ word in a post,

$p-$ post

Table 1. Number of subscribers of analyzed communities

\begin{tabular}{|l|c|l|c|}
\hline \multicolumn{1}{|c|}{ Community } & Number of subscribers & \multicolumn{1}{|c|}{ Community } & Number of subscribers \\
\hline alt-right-1 & 86644 & antifa-1 & 187 \\
\hline alt-right-2 & 16358 & antifa-2 & 136 \\
\hline alt-right-3 & 8911 & antifa-3 & 139 \\
\hline alt-right-4 & 11679 & antifa-4 & 118 \\
\hline alt-right-5 & 4470 & antifa-5 & 88 \\
\hline alt-right-6 & 5142 & antifa-6 & 73 \\
\hline alt-right-7 & 11449 & antifa-7 & 75 \\
\hline alt-right-8 & 183 & antifa-8 & 37203 \\
\hline mgtow-1 & 23134 & anarch-1 & 33419 \\
\hline mgtow-2 & 10821 & anarch-2 & 32257 \\
\hline mgtow-3 & 8450 & anarch-3 & 7061 \\
\hline mgtow-4 & 7518 & anarch-4 & 4120 \\
\hline mgtow-5 & 3443 & anarch-5 & 2131 \\
\hline mgtow-6 & 2447 & anarch-6 & 2181 \\
\hline mgtow-7 & 2501 & anarch-7 & 1112 \\
\hline mgtow-8 & 1109 & anarch-8 & \\
\hline
\end{tabular}


$|P|$ - number of posts in a text corpus,

$\left.\mid\left\{p_{i} \in P \mid w \in p_{i}\right\}\right) \mid-$ number of posts in a text corpus $P$, where $w$ occurs.

The list of the most relevant words for the radical online community is calculated on the basis of absolute importance:

$$
\text { weight }_{a b s}(w, C)=\frac{\sum_{1}^{n}\left(w e i g h t\left(w, p_{i}\right)\right.}{n_{p}}
$$

where

$C$ - radical community posts corpus $(C \in P)$,

$n_{p}$ - Number of posts in $C$, where $w$ occurs.

For further analysis, words with the 10 highest values of absolute relevance were selected, grouped by classes of radical ideological platforms.

\section{RESEARCH RESULTS}

Absolute relevance words assessment by classes of radical platforms revealed that high accuracy TF-IDF identifies words-triggers that are an important part of radical communities discourse. Herewith, in the communities of anarchists words-triggers protests in Belarus, which began in July 2020, were among the most relevant words. Thus, the anarchist communities turned out to be the most sensitive to the current political agenda. Table 2 lists the common words-triggers found, grouped by class. The first ten most relevant words for each radical community included from 3-7 words classified by the expert as words-triggers.

There is a heat map in figure 1 that reflects the crossing of relevant words for radical communities. The analysis of the map revealed that the most homogeneous discourse is in the MGTOW and AntiFa communities. In some cases, there is a significant crossing of relevant words between the Alt-Right and MGTOW communities (alt-right-1 and mgtow-2 communities), Alt-right and AntiFa (alt-right-3 and antifa-7 communities), as well as Alt-right and Anarchists (alt-right-3 and anarch-7 communities). However, a thorough results study showed that there are no coincidences of relevant words-triggers, but only of commonly used words. Consequently, the online communities' radical classes under study are not related to each other in a significant way on the basis of the topics discussed in their posts.

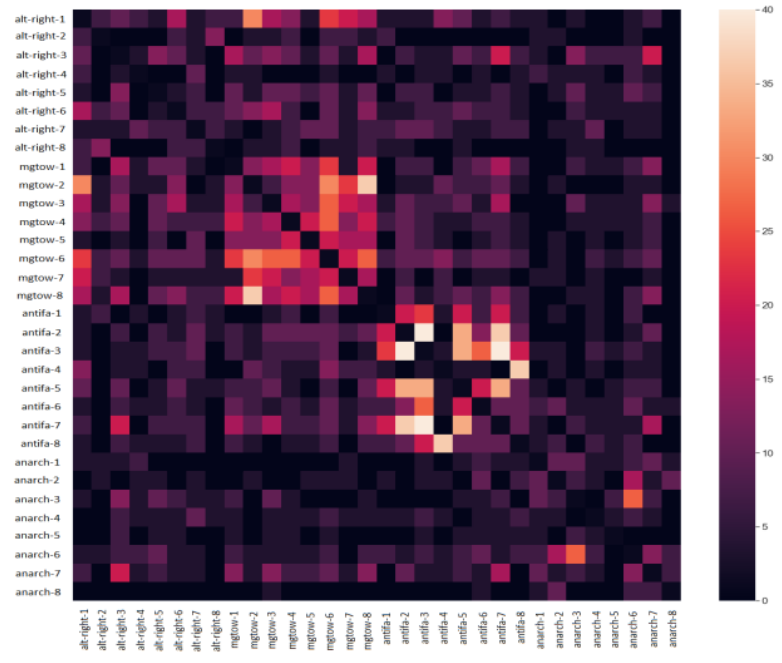

Figure 1 Heat map of relevant words crossing of radical online communities.

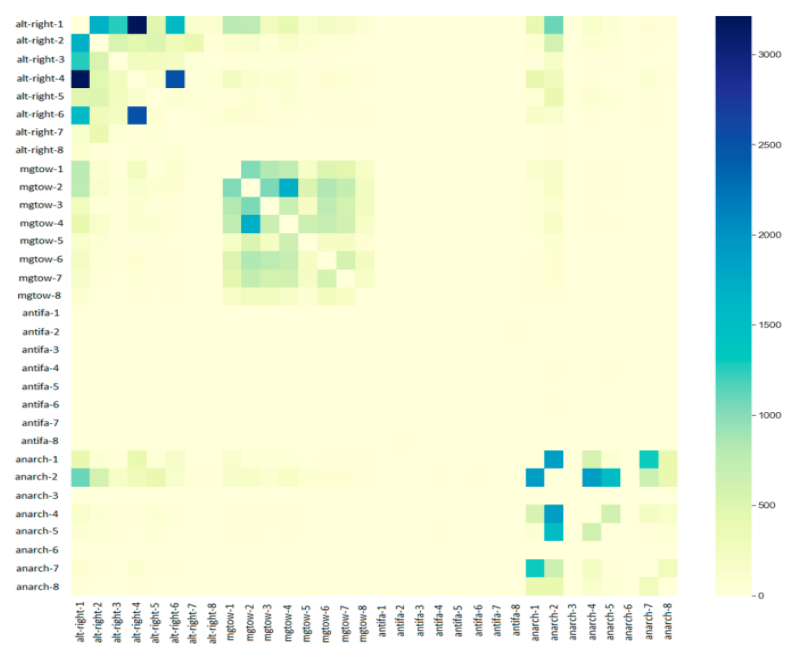

Figure 2 Heat map of subscribers crossing of radical communities.

There is a heat map in figure 2 that reflects the number of joint subscribers for radical online communities. Besides the AntiFa communities, all classes showed a relatively high level of subscribers crossing within themselves. As well Alt-right communities demonstrated significant absolute crossing with the MGTOW and Anarchist classes. The relative crossing values are not significant when compared to the total number of unique users. Solely the MGTOW class has about $5 \%$ of the general users with Alt-right. The

Table 2. The automated search result for relevant words

\begin{tabular}{|l|l|}
\hline \multicolumn{1}{|c|}{ Community class } & \multicolumn{1}{c|}{ Words-triggers obtained by TF-IDF method } \\
\hline Alt-right & white, right, anti-Bolshevism, Russia, Wrangel, Cutter, Russian, race, warrior \\
\hline MGTOW & feminism, male, harassment, child, wife, woman, mgtow \\
\hline AntiFa & fascism, fascist, antif, kill, Cutter, Donbass \\
\hline Anarchists & protest, Belarus, anarchist, Minsk, socialism, revolution, solidarity, commune \\
\hline
\end{tabular}


Table 3. Number of joint subscribers by radical communities classes

\begin{tabular}{|l|c|c|c|c|}
\hline & Alt-right & MGTOW & AntiFa & Anarchists \\
\hline Alt-right (119 246) & - & 2293 & 13 & 2865 \\
\hline MGTOW (47 265) & 2293 & - & & 724 \\
\hline AntiFa (916) & 13 & 2 & - & 74 \\
\hline Anarchists (2 865) & 2865 & 724 & 74 & - \\
\hline
\end{tabular}

comparative "isolation" of AntiFa can be manifested, among other things, as a result of the small number of unique subscribers with respect to other classes. Table 3 shows the aggregated result by the number of total subscribers, the total number of unique users is shown in parentheses, and the result is grouped by classes of radical online communities. In such a way, the obtained result is similar to the result indicated above - different classes of radical online communities do not have significant mutual connections as for the number of common users.

\section{DISCUSSION}

To test the presented hypothesis, a program code in Python 3 was designed and implemented. The following aspects were automated: data retrieval functions; assessment of words relevance used in posts of open radical online communities; calculation of the number of unique and joint subscribers at the level of individual online communities and classes of communities.

The use of the TF-IDF statistical measure to assess the relevance of the words allowed detecting also wordstriggers for ideological platforms. Accordingly, this approach can be used, among other things, when solving problems of classification and clustering of radical online communities (or radical texts). The presence of commonly used words among the relevant words may be associated with the text corpus shaping characteristics. To reach the more precise accuracy by (1) adding posts, that are not related to radical platforms, to the source code corpus, and (2) calculating the relevance of phrases rather than individual words (n-gramm).

\section{CONCLUSIONS}

In the scope of the present research, the hypothesis about the closedness of radical on-line communities compared with other ideological platforms is partially confirmed. Radical online communities are highly connected within their own ideological platforms. The communities related to Alt-right have the closest connections as far as the number of joint users. They are also the most numerous communities. The MGTOW communities as well showed strong connections, both in terms of commonly used relevant words and the number of joint subscribers. The Anarchists communities were the only ones among the studied who showed the presence of relevant words reflected the latest protest political agenda.

However, a high degree of isolation was revealed during the transition from the level of individual online communities to the level of communities classes united as per the principle of belonging to one ideological platform. Summing up what has been said, it can be affirmed that, within their ideological platform, radical communities exist in the so-called "echo chambers" - a situation where ideas and beliefs typical of the platform are intensified and reinforced by means of numerous repetition of the message within a closed system.

\section{ACKNOWLEDGMENTS}

The reported study was funded by RFBR and EISR, project number 20-011-31583.

\section{REFERENCES}

[1] M. Hall, M.K. Logan, G.S. Ligon, D.C. Derrick, Do Machines Replicate Humans? Toward a Unified Understanding of Radicalizing Content on the Open Social Web, Iss. 12(3), 2019. DOI: https://doi.org/10.1002/poi3.223

[2] L. Farago, A. Kende, P. Kreko, Justification of intergroup violence - the role of right-wing authoritarianism and propensity for radical action, Dynamics of Asymmetric Conflict, Iss. 12(2), 2019. DOI: https://doi.org/10.1080/17467586.2019.1576916

[3] R.L. Breiger, G.A. Ackerman, V. Asal, D. Melamed, H.B. Milward, R.K. Rethemeyer, E. Schoon, Application of a Profile Similarity Methodology for Identifying Terrorist Groups that Use or Pursue CBRN Weapons, Computing, Behavioral-Cultural Modeling and Prediction, 6589, 2011, DOI: https://doi.org/10.1007/978-3-64219656-0_5

[4] J.W. Pennebaker, R.J. Booth, R.L. Boyd, M.E. Francis, Linguistic Inquiry and Word Count: LIWC2015, Operator's Manual Austin, TX: Pennebaker Conglomerates, 2015. Retrieved from: https://s3-us-west- 
2.amazonaws.com/downloads.liwc.net/LIWC2015 OperatorManual.pdf

[5] D.K. Lyons. Analyzing the Effectiveness of $\mathrm{Al}$ Qaeda's Online Influence Operations by Means of Propaganda Theory, The University of Texas at El Paso, 2013, 93 p.

[6] A. Sureka, S. Agarwal, Learning to Classify Hate and Extremism Promoting Tweets, Intelligence and Security Informatics Conference, The Hague, 2014, p. 320. DOI: https://doi.org/10.1109/JISIC.2014.65

[7] R. Lewis, Alternative Influence: Broadcasting the Reactionary Right on YouTube, Report, Data \& Society's Media Manipulation research initiative, 2018. Retrieved from: https://datasociety.net/wpcontent/uploads/2018/09/DS_Alternative_Influenc e.pdf

[8] M. Vergani, M. Iqbal, E. Ilbahar, G. Barton, The Three Ps of Radicalization: Push, Pull and Personal, A Systematic Scoping Review of the Scientific Evidence about Radicalization Into Violent Extremism, Studies in Conflict \& Terrorism, Iss. 43(10), 2018.

DOI: https://doi.org/10.1080/1057610X.2018.1505686

[9] P. Gill, J. Horgan, P. Deckert, Bombing Alone: Tracing the Motivations and Antecedent Behaviors of Lone-Actor Terrorists. Journal of Forensic Sciences, Iss. 59(2), 2014. DOI: https://doi.org/10.1111/1556-4029.12312

[10] S. Fahey, P. Simi, Pathways to Violent Extremism: a Qualitative Comparative Analysis of the US FarRight, Dynamics of Asymmetric Conflict, 2018. DOI: https://doi.org/10.1080/17467586.2018.1551558

[11] Fact Sheet: Far-Right Fatal Ideological Violence against Religious Institutions and Individuals in the United States: 1990-2018. Retrieved from: https://www.start.umd.edu/pubs/START_ECDB_F arRightFatalIdeologicalViolenceAgainstReligiousT argets1990-2018_Oct2018.pdf

[12] T.J. Holt, M. Stonhouse, J. Freilich, S.M. Chermak, Examining Ideologically Motivated Cyberattacks Performed by Far-Left Groups, Terrorism and Political Violence, 2019. DOI: https://doi.org/10.1080/09546553.2018.155121

[13] M. Caiani, The Rise and Endurance of Radical Right Movements, Current Sociology, Iss. 67(6), 2019, DOI: https://doi.org/10.1177/0011392119868000

[14] C. Mudde, The Far Right Today. Cambridge, UK, Polity Press, 2019, 205 p. 